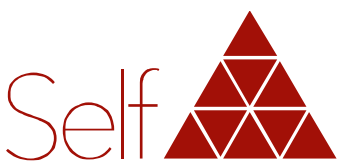

Revista do Instituto Junguiano de Săo Paulo

\title{
Violência psicológica na família e a manifestação do complexo de bode expiatório
}

\author{
Giovana COUTINHO \\ Belo Horizonte, MG, Brasil.
}

\section{Resumo}

A temática do bode expiatório, na abordagem psicológica, é terreno riquíssimo e elucidativo de uma série de fenômenos observados no cotidiano dos consultórios. Este trabalho foi desenvolvido a partir da compreensão dos primeiros passos da construção da personalidade humana, por meio do estudo das representações da criança na família, desde os primórdios da história, analisando como a atenção dispensada a ela pelos adultos atua na sua psique quando ela chega à idade adulta. A exposição a fatores que influenciaram as famílias na maneira como elas têm visto as crianças ao longo dos séculos é um dado ontológico assimilado pelo inconsciente coletivo, criando um registro no psiquismo, nomeado por sua vez como arquétipo pela psicologia analítica. A questão apresentada neste artigo busca apontar as origens daquilo que hoje é identificado como o complexo do bode expiatório, que tem como base o arquétipo do bode expiatório. $\bigcirc$ propósito de relacionar o tema à violência psicológica é uma provocação,

Conflito de interesses:

A autora declara não haver nenhum interesse profissional ou pessoal que possa gerar conflito de interesses em relação a este manuscrito. com o objetivo de levar o leitor a refletir sobre o produto de tal associação. O filme "Gente como a Gente" (Ordinary people) é usado para articular, simbolicamente, a ocorrência do fenômeno do bode expiatório na família.

\section{Descritores}

violência na família, complexo, psicologia junguiana, bode expiatório. 


\title{
Psychological violence in the family and the manifestation of scapegoat complex
}

\begin{abstract}
The theme of the scapegoat in the psychological approach is a very rich and meaningful territory for a series of phenomena observed daily in clinical practice. This work was developed from an understanding of the initial steps of construction of the human personality, through a study of the representation of children in the family since the dawn of history, and analyzing how the attention given to the child by adults will act on the child's psyche during the process of reaching adulthood. The exposure to factors that influenced the family, in terms of how the child was viewed over centuries, consists of an ontological record assimilated by the collective unconscious, creating, in turn, a record in the psyche denominated as archetype by analytical psychology. The question presented sought to determine the origins of what is now identified as the scapegoat complex, and which has as its base the scapegoat archetype. The purpose of relating the issue to the issue of psychological violence is a provocation, in order to lead the reader to reflect on the product of such an association. The film "Ordinary People" was used as a way to symbolically articulate the occurrence of the phenomenon of the scapegoat in the family.
\end{abstract}

\section{Descriptors}

family violence, complex, Junguian psychology, scapegoat. 


\title{
La violencia psicológica en la familia y la demostración del complejo de chivo expiatorio
}

\begin{abstract}
Resumen
El tema del chivo expiatorio, en el enfoque psicológico, es un terreno riquísimo y aclaratorio de una serie de fenómenos que se encuentran cotidianamente en los consultorios. Este trabajo fue desarrollado a partir de la comprensión de los primeros pasos en la construcción de la personalidad humana, a través del estudio de las representaciones del niño en la familia desde los primordios de la historia, haciendo el análisis de cómo la atención prestada a los niños por los adultos actúa en su psique cuando se convierte en un adulto. La exposición a los factores que influyeron en las familias en la manera como perciben a los niños a lo largo de los siglos es un registro ontológico asimilado por el inconsciente colectivo, creando un registro en la psique nombrada, a su vez, como arquetipo por la psicología analítica. La información presentada en este artículo, busca señalar los orígenes de lo que ahora se identifica como el Complejo de Chivo Expiatorio, que se basa en el arquetipo del chivo expiatorio. El propósito de relacionar el tema a la cuestión de la violencia psicológica fue añadido de manera provocativa, con el fin de llevar al lector a reflexionar sobre el producto de tal asociación. La película "Gente como Uno" (Ordinary people) se utilizó como forma de articular, simbólicamente, la ocurrencia del fenómeno del chivo expiatorio en la familia.
\end{abstract}

\section{Descriptores}

violencia doméstica, complejo, psicología junguiana, chivo expiatorio. 


\section{Introdução}

Partindo de uma reconstrução sintetizada do processo histórico do desenvolvimento do modelo de família à delimitação de papéis e condutas no espaço doméstico, somadas a uma reunião de conteúdos de mitos e vivências relacionados ao tema, ao longo da história da humanidade, busca-se a reconstrução do percurso que conduz à representação contemporânea de família, tomada como berço do mundo infantil. Posteriormente, descreve-se o modo como o complexo de bode expiatório se constitui na psique humana e as consequências de certas experiências infantis, tanto nesse período, quanto na vida adulta. Trata-se então dos arquétipos (Pieri, 2002): conteúdos originais que foram acumulados na psique ao longo do percurso da humanidade e que em algum momento emergiram, passando a atuar de forma autônoma na conduta humana. Os arquétipos são formas típicas do modo de pensar e de agir do homem, sendo assim uma possibilidade inata da atividade imaginativa. Jung emprega tal terminologia para conceituar alguns dos conteúdos da parte mais profunda do inconsciente.

O filme "Gente como a gente" (Schwary, 1980) oferece a possibilidade de correlacionar os aspectos teóricos à história narrada na tela. Valendo-se desse recurso, filme e fundamentação teórica serão conjugados de maneira a ilustrar mais claramente o objeto deste artigo.

\section{Sinopse do filme}

Baseado no romance homônimo de Judith Guest, "Gente como a gente" é um drama que estreou em 1980, dirigido por Robert Redford e vencedor do prêmio Oscar de melhor filme, melhor diretor, melhor ator coadjuvante e melhor roteiro adaptado.

filme retrata a morte prematura, em um acidente, de Buck, o filho mais velho de uma família de classe média alta residente em um rico subúrbio de Chicago. $O$ acontecimento afeta toda a família, principalmente o irmão da vítima, Conrad, que, sentindo-se responsável pelo ocorrido, fica internado em um hospital psiquiátrico em tratamento. A mãe, Beth, uma matriarca fria, insiste em manter as aparências para não dar a entender que a unidade da família foi quebrada após a morte do primogênito. Ela também enfrenta outra crise, a culpa que Conrad, agora filho único, passa a sentir pela morte do irmão. $\bigcirc$ pai, Calvin, é um homem dedicado e se esforça para manter a família unida, mesmo com os conflitos existentes entre ele e a esposa.

Conrad, retornando ao lar, findo o período de internação psiquiátrica, começa a vivenciar intensas dificuldades nas suas relações com outros adolescentes, na escola e demais ambientes onde transita. A relação do filho com a mãe mostra-se bastante delicada devido ao fato desta tratá-lo de uma maneira hostil e velada. Tal conduta materna agrava muito o debilitado estado emocional de Conrad. 
Pesadelos constantes e isolamento social são alguns dos sintomas relevantes apresentados pelo adolescente, que se vê impossibilitado de prosseguir com suas atividades rotineiras e sua vida social. As cobranças sobre o porquê de suas mudanças comportamentais que chegam de todos os lados - amigos, professores e família -, associadas ao intenso sentimento de desconforto diante da forma como aconteceu a morte do irmão, levam-no a buscar ajuda profissional, que ele se recusava a aceitar, apesar de já ter recebido orientação profissional para a continuidade do tratamento pós-internação em instituição psiquiátrica.

Conrad retoma o tratamento psiquiátrico fora da instituição de saúde mental e consegue aos poucos superar as dificuldades. $\bigcirc$ pai também procura ajuda profissional, enquanto a mãe se nega a buscar tratamento, terminando por abandonar a família.

filme mostra a desestruturação emocional dos membros da família a partir da morte de Buck. Após a tragédia, pai, mãe e o filho caçula passam a viver uma situação conflituosa no convívio familiar. Aparentemente, a morte do irmão faz Conrad constelar o complexo de bode expiatório, que irrompe a partir da vivência de um sentimento de culpa supostamente gerado pela situação de morte. É importante ressaltar que este sentimento de culpa sempre esteve presente na consciência de Conrad, sendo demonstrado em várias outras situações do filme, ou seja, é um sentimento que se apresenta como inerente ao rapaz, à medida que se encontra evidente desde a infância. Isso é apontado por Neumann (1991) como sentimento primordial humano, mas também está relacionado aos sintomas descritos como característicos do complexo de bode expiatório. Nesse sentido, a vivência insuportável desse sentimento leva Conrad à tentativa de suicídio, cortando os pulsos, o que resulta na sua internação por três meses em um hospital psiquiátrico.

Algo muito marcante na história do filme é justamente a observação sobre o que antecede em sua vida. Sua biografia foi sempre marcada pela discriminação familiar, exclusão, rejeição materna e desamparo. Esses atributos negativos, que estão presentes em demasia na relação dos pais com Conrad, estão relacionados às projeções da própria sombra deles sobre o filho. Em muitos momentos fica evidente que, desde a infância, Conrad vivenciava sentimentos de exclusão e de inadequação advindos da sua relação com a mãe. A hostilidade de Beth em relação a Conrad é anterior ao acidente e morte do primogênito.

A ausência de funcionalidade da família demonstra-se pela crise conjugal entre Calvin e Beth. Bastante afetados pela morte do filho mais velho, eles usam este acontecimento para tentar justificar os problemas no casamento que, na realidade, precedem a todos os fatos.

A seguir apresenta-se o início da concepção de família, em uma perspectiva cronológica, analisando os diferentes momentos vividos por essa instituição. Posteriormente, abordam-se os conteúdos que envolvem o papel da criança 
nas famílias, a conceituação e a definição histórica de bode expiatório, bem como as relações simbólicas entre o filme e o tema.

\section{Evolução histórica da família}

Ariès (2006) aponta que no período Paleolítico foram inscritos, sob a forma de pinturas rupestres, os primeiros registros sugestivos da existência de um tipo de organização social, podendo ser comparada ao que bem depois veio a ser denominado de "família". Tais imagens sugerem que esses indivíduos se agrupavam segundo sexo e idade e que, provavelmente, tinham definições de papéis, ou seja, as mulheres cuidando da colheita, dos idosos e das crianças, enquanto os homens jovens e maduros caçavam.

Esse mesmo autor (Ariès, 2006) reitera que não há na história dos povos antigos, bem como da Antiguidade Oriental e Clássica, o surgimento de uma sociedade organizada sem que se vislumbre uma base, ou seus fundamentos, na família ou organização familiar. $\bigcirc$ próprio modelo de família brasileiro encontra sua origem na família romana que, por sua vez, foi estruturada pela influência do modelo grego.

Ariès (2006) aponta que familiar, na época mais medieval, englobaria toda pessoa que vivesse na mesma casa, sem considerar a questão de sangue incluindo aí servos, empregados, parentes distantes.

O termo "família" é derivado do latim famulus, que significa "escravo doméstico" (Alves, 1977). Esse termo foi criado na Roma antiga para designar um novo grupo social que surgiu com a união de trinta aldeias e tribos latinas que, por volta do século VII, agrupavam-se ao redor de Roma e que formaram uma confederação. Elas se organizaram para assegurar a própria defesa, quando da introdução da agricultura e da escravidão legalizada. É importante ressaltar que o conceito de família não é único ao longo da história e vem sofrendo diferenciações segundo as culturas e épocas.

\section{Breve percurso sobre o papel da criança ao longo dos tempos}

Alguns fatores evidenciaram como foi construído o imaginário social em relação à criança. $\bigcirc$ sentimento de indiferença a ela dirigido demonstra a negligência e a negação do reconhecimento de suas necessidades básicas. narcisismo do adulto ocupou o lugar do reconhecimento da singularidade do universo infantil.

Em um cotejamento entre Badinter (1985) e Ariès (2006), percebe-se que ambos apontam a ausência de um sentimento diferenciado em relação à infância. Trata-se, pois, de perceber a necessidade de um tratamento diferenciado às crianças em razão das particularidades da fase infantil. Sabe-se que elas entravam precocemente no mundo dos adultos e não se distinguiam mais deles. Segundo Ariès (2006), sentindo-se irritado e demonstrando hostilidade, argumenta: 
Não posso conceber essa paixão que faz com que as pessoas beijem as crianças recém-nascidas, que não têm ainda nem movimento de alma, nem forma reconhecível no corpo pela qual se possam tornar amáveis, e nunca permiti de boa vontade que elas fossem alimentadas na minha frente (Montaigne, 1595, p. 159, citado por Ariès, 2006, p. 101).

Durante muitos séculos, era costume separar as crianças da sua família de origem e entregá-las a amas de leite. Posteriormente, elas eram educadas por pessoas ou famílias destinadas a essa função. Essa prática afetava profundamente o estabelecimento de laços afetivos entre pais e filhos porque, mesmo que os filhos retornassem ao lar de origem, o vínculo entre eles já havia sucumbido à separação. $\bigcirc$ índice de mortalidade infantil era tremendo e se relacionava com as mais diversas causas, inclusive a falta de higiene.

A roda dos enjeitados ou expostos, comum no século XVIII, foi mais uma das marcas das condutas discriminatórias em relação à criança. Consistia em descartar uma criança cuja gravidez foi indesejada pela mulher ou por sua família, que considerava a criança como fruto de uma aventura, oriunda de relações proibidas. Eram entregues ali também os filhos das prostitutas. A criança era depositada em uma das aberturas de um cilindro giratório, que ficava próximo à entrada de conventos, mosteiros ou clausuras. Nessa abertura lateral eram colocados geralmente objetos, utensílios ou alimentos destinados a esses locais. Após a entrega da "encomenda" tocava-se uma sineta para avisar quem estivesse do outro lado. As crianças deixadas ali muitas vezes traziam fitinhas ou medalhinhas, entre outros adereços de identificação, para que suas mães, talvez, pudessem reencontrá-las.

Ariès (2006) demarca a entrada no século XVII como um período de mudança na concepção até então dada à infância. A família, ainda diferente daquela que viria a ser vislumbrada na modernidade, tem suas sementes dos valores, que florescerão posteriormente, lançadas nessa fase. A imagem infantil ainda amedronta devido às ideias da filosofia e da teologia. Esta última relacionou a imagem da criança ao nascer como símbolo da força do mal, um ser imperfeito, esmagado pelo peso do pecado original.

Santo Agostinho (400 d.C./2002, p. 251) acredita no "pecado da infância" porque o filho do homem é ignorante, apaixonado e caprichoso e ainda completa dizendo que "se o deixarmos fazer o que lhe agrada, não há crime em que não se precipitaria" (p. 251). Completa suas concepções declarando "Fui concebido na iniquidade... é no pecado que minha mãe me gerou..., portanto, Senhor, onde e quando fui inocente?" (p. 251). Para Santo Agostinho (400 d.C./2002) de nada difere o pecado de uma criança do pecado de seu pai. Neste ínterim repousa a visão da criança e da infância neste contexto histórico.

A educação principiada na infância toma força, sendo revestida de seu denso significado originado do latim educare, que significa: endireitar o que é torto ou malformado. Assim, persiste uma concepção distorcida ou 
tendenciosa a respeito da criança. A imagem infantil ainda permanece polarizada e presa ao aspecto nefasto do arquétipo do puer.

A predominância do pensamento agostiniano perdurou por longo período na prática da pedagogia e das escolas. Descartes, pensador da filosofia moderna, de certo modo, coaduna suas ideias com as de Santo Agostinho quando afirma que:

A desgraça é que as opiniões adquiridas na infância são as que marcam mais profundamente o homem. É preciso nada menos que toda uma vida para eliminar esses maus hábitos. Mesmo assim, poucos o conseguem. Em sua maioria, os homens estão condenados, pela falta de caráter e de inteligência, a permanecer presos à sua infância (Descartes, 1637/1999, p. 183).

Com o decorrer do tempo mudanças profundas aconteceram nas famílias e no papel da criança. Regidas pelo modelo do patriarcado, as famílias no século XIX eram constituídas a partir da decisão do chefe - o pai - que determinava os costumes e hábitos, além de decidir com quem e como deveriam se estabelecer as uniões e os casamentos. $\bigcirc$ escalonamento social era o parâmetro empregado para definição e escolha dos casais nas uniões. Sob a ótica do afeto, da estima e da dedicação, apenas as famílias mais humildes firmavam suas uniões. Entre as famílias mais abastadas prevalecia o jogo de interesses financeiros e políticos.

A urbanização consolida a organização social e a separação de quartos e aposentos para os membros da família, desconstruindo, dessa forma, seu caráter público e criando novos preceitos morais. Os valores pós-guerra são remodelados e, na década de 1970, a mulher pode experimentar a emancipação sexual por meio do uso da pílula anticoncepcional.

A família, no século XX, vivencia a quebra do resguardo doméstico, no qual a mulher se dedicava exclusivamente aos afazeres do lar, enquanto o homem era o único provedor das despesas. Muitas mulheres passaram a ter dupla jornada de trabalho porque tinham que se dedicar aos afazeres domésticos à noite, quando retornavam ao lar após o trabalho remunerado que executavam durante $\mathrm{o}$ dia. As crianças, que já estavam bastante envolvidas no ambiente escolar desde os fins do século XVIII, passaram a ficar sob os cuidados de babás ou em creches em horário integral. Destacase que hoje pode se verificar uma forma de retrocesso, com a educação infantil voltando a obedecer ao modelo de terceirização da função paternomaterna ou familiar.

Conclui-se, então, que as famílias, no decorrer dos tempos, passaram por diferentes fases, sofrendo paulatinamente alterações na sua dinâmica interna. Refazendo costumes e valores e reorganizando-se no sentido de um funcionamento mais adequado conforme as exigências sociais de cada época. $\bigcirc$ movimento de suas transformações foi sempre em direção a uma resposta social mais adequada aos valores vigentes. 
Quanto ao papel da criança na família, ao longo da história, observa-se que este sempre foi secundário e sem relevância no âmbito familiar. Atribuiuse a ela funções servis, de criadagem e utilitárias. Durante séculos sua imagem esteve associada à figura demoníaca ou carregada de imperfeições e pecados. Durante um longo período, a criança sofreu total negligência por parte dos adultos que a expunha a situações inadequadas para o seu amadurecimento psicoemocional. Nem nas questões relacionadas à saúde, a criança foi objeto de preocupação. Hoje, sabe-se que o processo de maturidade infantil depende de condições como ambiente familiar equilibrado e saudável, alimentação adequada, segurança e acolhimento.

No dia 20 de novembro de 1989, representantes de vários países aprovaram a "Declaração dos Direitos da Criança", uma adaptação da "Declaração Universal dos Direitos Humanos", voltada para as crianças. De modo geral, os direitos das crianças (Brasil, 2013) são os seguintes:

1. Todas as crianças têm o direito à vida e à liberdade.

2. Todas as crianças devem ser protegidas da violência doméstica.

3. Todas as crianças são iguais e têm os mesmos direitos, não importa sua cor, raça, sexo, religião, origem social ou nacionalidade.

4. Todas as crianças devem ser protegidas pela família e pela sociedade.

5. Todas as crianças têm direito a uma nacionalidade.

6. Todas as crianças têm direito à alimentação e ao atendimento médico.

7. As crianças portadoras de dificuldades especiais, físicas ou mentais, têm o direito à educação e a cuidados especiais.

8. Todas as crianças têm direito ao amor e à compreensão dos pais e da sociedade.

9. Todas as crianças têm direito à educação.

10. Todas as crianças têm direito de não serem violentadas verbalmente ou serem agredidas por pais, avós, parentes, ou mesmo a sociedade.

\section{Bode expiatório}

Entende-se por bode expiatório a designação de uma pessoa sobre a qual recai uma culpa, mesmo que ela não tenha de fato cometido o ato pelo qual é acusada. Essa referência remonta a tempos arcaicos, quando vítimas humanas ou animais eram escolhidas para o sacrifício ao Deus do mundo subterrâneo, a fim de aplacar sua ira e purificar a comunidade. Acreditavase que transferindo magicamente o mal cometido para um animal ou humano, este mal poderia ser eliminado, reduzindo a fúria divina e restabelecendo assim as relações com Deus.

As escrituras judaicas descrevem uma prática, como parte de uma cerimônia realizada no Dia da Expiação, de expulsão do bode expiatório da 
comunidade em expiação aos pecados dos israelitas. $\bigcirc$ bode expiatório era, portanto, um pharmakon, isto é, um remédio, um agente de cura.

O ritual hebraico do Yom Kippur, o dia do perdão, que faz parte das festividades do Ano Novo do povo hebreu exprime bem o sentido deste tipo de cerimônia. Nele um bode era sacrificado e oferecido a Jeová, para perdoar e purificar Israel por todos os pecados cometidos. Já o bode errante era dedicado ao deus ctônico Azazel que carregava para o deserto os pecados e a culpa dos israelitas (Perera, 1986, p. 15).

objetivo desse ritual, em tempos remotos, era o de expulsar males que afligiam a sociedade, como a morte, a enfermidade, a violência, o sofrimento físico ou psíquico, ou mesmo, o sentimento de culpa e o pecado, que acompanham a consciência de transgressão ao código moral.

Os bodes expiatórios estão presentes ao longo da história da humanidade, assim, nessa expressão, entende-se também a indicação da presença de um arquétipo. Evidências de rituais dessa natureza envolvendo animais sacrificiais estão descritas em culturas muito antigas e em sociedades primitivas como os astecas e os maias (Bartlett, 2011); no hinduísmo védico (Vaithligam \& Sekhar, 2010); no islamismo do Alcorão (El Hayek, 2012); e entre os gregos e romanos (Brandão, 2007).

\section{O complexo de bode expiatório}

Os complexos são conteúdos básicos do nosso inconsciente pessoal; são agrupamentos de imagens ligadas por tônus emocionais comuns. Jung (1967/1984) aponta os complexos como via régia de acesso para o inconsciente. $\bigcirc$ papel deles é predominante na psicologia profunda, pois se constituem como reunião de ideias de acento emocional no inconsciente. Cada complexo é formado por um elemento nuclear portador de um significado que está fora da vontade consciente, portanto, inconsciente. Ele pode manifestar todos os graus de autonomia.

Perera (1986) considera que, em termos junguianos, o complexo de bode expiatório é um recurso de negação sombra. Segundo a autora, na atualidade os indivíduos identificados com o complexo de bode expiatório vivenciam uma distorção patológica da estrutura arquetípica do ritual hebraico descrito na Bíblia (Levítico, Cap. 16, versículos 5-28), quando um animal era oferecido em sacrifício com o objetivo de expulsar do povo os males a ele impingidos. Por complexo psicológico de bode expiatório entende-se um agrupamento de conteúdos com o mesmo tônus emocional que se encontra fora da consciência, portanto, na sombra. A projeção destes conteúdos está relacionada, na maioria das vezes, a julgamentos morais, tais como o que é feio, errado, ruim ou certo. Isso ocorre na relação entre a criança e as figuras preponderantes a ela. Estas figuras projetam de forma maciça sobre a criança conteúdos inaceitáveis de si mesmas. Esses conteúdos projetados são assimilados pela criança e incorporados ao 
sentimento de culpa primordial, conforme descrito por Neumann (1991), que é inerente à psique humana. Tendo em sua base o arquétipo do bode expiatório, o complexo passa a repousar em estado de latência no inconsciente até que uma constelação adequada o traga para a consciência.

O filme "Gente como a Gente" é usado para articular, simbolicamente, a ocorrência do fenômeno do bode expiatório na família, Calvin, o pai, intermedia uma discussão entre os filhos Conrad e Buck: é notória a argumentação dele tentando convencer Conrad de que exigir seus direitos, no caso o suéter do qual seu irmão havia se apropriado, era inadequado e feio. Sabemos que as colocações feitas pelas figuras representativas na vida da criança são muito importantes porque contribuem para a construção da autoimagem. $\bigcirc$ mecanismo projetivo utilizado por Calvin revela muito da própria personalidade do pai, bem como de sua conduta passiva e introvertida. A projeção do pai em relação ao filho caçula é evidenciada em muitos momentos do filme.

Segundo Jung (1971/1984), durante os dois ou três primeiros anos de vida, a criança tem uma psique extremamente influenciável e dependente por completo da psique dos pais, dos quais só mais tarde poderá se libertar ou não. A criança vive em estado indiferenciado por seu baixo nível de consciência. Portanto, ainda não existe um eu claramente diferenciado do resto das coisas. Tudo o que pertence a ela, pertence a qualquer outro. Jung dizia que esse estado era como a "participação mística" que acontece com os povos primitivos, sendo a criança tão carente de consciência como o homem primitivo, sem condição de se proteger contra o que acontece no seu grupo.

Sobre o sentimento de culpa primordial de origem arcaica que segrega e estigmatiza crianças, em um momento posterior, fazendo-as sentir-se como o bode expiatório na família. Trata-se de uma reedição de algo já inscrito na psique infantil e que recebe, num outro momento, uma conotação que vem acrescentar significado a anterior (Neumann, 1968, p. 70).

A criança traz consigo o arquétipo da grande mãe. Influenciada por esse arquétipo, projeta sobre a mãe a autoridade, o caráter mitológico e até mesmo numinoso. A mãe pessoal evoca a mãe arquetípica na psique da criança e, como representação arquetípica, ela é carregada de sentidos positivos (nutridores e favoráveis) e negativos (nefastos e destruidores). A imago da mãe tem um significado muito pessoal, cada criança tem a "sua mãe". Existe a mãe pessoal e a mãe arquetípica. A vivência com a mãe pessoal é imprescindível para a criança criar essas imagens, projeções e fantasias. As representações arquetípicas e inconscientes da mãe somadas às imagens da mãe pessoal é que predefinem o relacionamento entre a mãe e a criança.

Nesse estado de fusão dá-se início ao jogo das projeções em relação à criança. A expectativa em relação ao futuro do petiz acontece desde a 
gestação, quando a fantasia dos pais sobre o futuro do bebê começa a tomar forma. Em geral, pretende-se para os filhos tudo aquilo que ficou irrealizável na vida dos pais. Os desejos e projetos de vida são, então, depositados naquele ser que nem mesmo chegou ao mundo. As projeções são as mais diversas possíveis e vão desde o desejo de que aquela criança seja o filho ideal, o mais bonito, educado, comunicativo, polido, estudioso, até uma variedade imensa de predicados. A criança chega ao mundo carregada de significados para seus pais e com um suposto compromisso de atendê-los em suas aspirações em relação a eles.

Beth, a matriarca do filme, em muitos momentos sugere sofrer de um comprometimento chamado alexitimia (APA, 2015), que na psicologia analítica pode ser compreendido como um transtorno no complexo do eu que ocasiona uma série de dificuldades nos relacionamentos sociais. $\bigcirc$ mais marcante nessa mulher, entretanto, é a subjugação sofrida pelo complexo materno negativo na sua relação com Conrad. Tal constelação Ihe confere uma persona materna absolutamente hostil, fria e indiferente às necessidades de Conrad.

Sua agressividade dissimulada em relação ao filho fica corroborada em vários momentos do filme. Ela tenta demonstrar um cuidado, um afeto em relação a ele, mas suas atitudes parecem ser, na verdade, ambivalentes. Em algumas cenas, quando é retratada a relação da mãe com o primogênito, fica evidente a presença do complexo materno positivo acrescido de uma sugestiva dose de sedução direcionada ao primogênito.

A dificuldade em expressar seus sentimentos ocasiona em Beth uma paralisia, um embotamento afetivo, uma relação disfuncional entre ela e o filho e o efeito devastador dessa tragédia. A atuação do complexo materno negativo é percebida de forma bem objetiva nessa personagem. Pode-se afirmar que o complexo materno positivo proporciona à criança um sentimento de direito à existência, e as necessidades emocionais e físicas são vivenciadas de modo a serem supridas sem maiores transtornos, o que não é observado no caso de Conrad. De modo geral, a mãe, ou sua representante, sendo aquela portadora do complexo materno, pode constelar ambos os aspectos do complexo. Sendo assim, a personagem Beth manifesta tanto um lado nefasto na sua relação com o filho caçula, como uma conduta benéfica ou favorável em relação ao primogênito Assim, as questões expressadas no relacionamento do jovem com sua mãe antecedem a morte do irmão, portanto, não podendo ser compreendidas como resultado do trauma vivido pelo incidente ocorrido com Buck. O filme apresenta cenas que confirmam a relação nociva entre a mãe e o filho caçula.

Já nos contatos com os primeiros grupos sociais, que geralmente se estabelecem na escola, a criança pode começar a apresentar os sinais da "contaminação" pelo complexo de bode expiatório. Sempre preocupada em agradar os colegas, desejando a qualquer custo pertencer e, de forma exagerada, se integrar ao grupo. $\bigcirc$ amor e reconhecimento tanto da 
professora como dos colegas é crucial. Para obter esse status, ela pode começar a se tornar servil, submetendo-se inquestionavelmente às regras impostas. É nesse contexto que se iniciam as primeiras vivências do complexo. Por se sentir inadequada, sentimento trazido da relação com seus pais, por não ter correspondido às expectativas dos mesmos, justamente porque é impossível agradar a todos em todos os momentos, ela tende a acreditar que é incapaz de se relacionar com o outro e começa um infindável jogo de agrados em suas relações interpessoais. Mais e mais é rechaçada no grupo, pois, desconhecendo a si mesma, acredita ser o que o outro lhe atribui. Conforme dito por Vanda di Yorio Benedito (comunicação pessoal, 22 de maio de 2015): "somos um cabide para as projeções do outro". E é nesse sentido que a criança aceita e admite as projeções que os outros depositam nela. A partir das projeções oriundas do lar é que a criança compreende quem é e segue acreditando nisso.

De acordo com Colman (1995), outra característica relacionada diretamente ao complexo de bode expiatório é a habilidade em conter e suportar o sofrimento. A visão distorcida da realidade é evidente em Conrad, o que pode ser observado nas suas relações sociais e com seu grupo de colegas na escola. Uma atitude de isolamento e dispersão é observada pela esquiva em estar com os colegas e também em interagir com eles. Nesse sentido, ele mesmo se coloca em uma posição de afastamento e discriminação em relação ao grupo (Colman, 1995). Assim, Conrad está mergulhado e completamente tomado pelo complexo de bode expiatório e faz-se excluído perante o grupo, o que provoca uma reação aversiva do grupo em relação a ele. O agente mais nocivo à cura de Conrad é o sentimento de culpa. Ele sente-se responsável diante de todos os problemas familiares e, de uma forma geral, dos problemas de todos que se relacionam com ele. A sensação ligada ao sentimento de culpa é a de paralisação: o indivíduo fica estático diante das situações conflitivas do dia a dia. É assim que o rapaz responde emocionalmente às situações que the são colocadas.

A criança escolhida como vítima, em geral é a mais forte no núcleo familiar, pois consegue carregar a tão temida sombra, o que incita a inveja dos pais. Por outro lado, a criança se vê incapaz de atingir os ideais estipulados pelos pais, sentindo-se inadequada e culpada. A raiva e a carência permanecem dissociadas, a noção de bem e mal, extremamente radical não encontrando o equilíbrio entre os opostos (Penna e Guidugli, 2005, p. 2).

Em 2002, Rivka Yahav e Shlomo A Sharlin, da Universidade de Haifa, em Israel, publicaram um estudo sobre conflitos familiares. A amostragem envolveu 161 indivíduos, entre crianças e jovens de ambos os sexos, com idades entre 10 e 17 anos e, também, portadores de sintomas orgânicos ou psicóticos. $\bigcirc$ objetivo foi pesquisar em que grau essas pessoas se sentiam injustamente responsabilizadas por outros familiares nos conflitos em seus lares. $\bigcirc$ trabalho apresentou os seguintes resultados: 
1. "As crianças responsabilizadas por conflitos familiares tendem a sentir-se como bodes expiatórios".

2. $\bigcirc$ uso de mecanismos de defesa tais como cisão, projeção e identificação projetiva, pode ser um indicativo do processo de bode expiatório.

3. Os resultados da investigação indicam uma conexão entre os sintomas e a culpa percebida empiricamente, sugerindo que a rejeição é um dos componentes na dinâmica familiar de crianças deprimidas.

4. Essa culpa demonstrada no estudo está presente em correlação significativa com os sintomas encontrados em crianças, podendo ter uma influência decisiva sobre o desenvolvimento patológico das mesmas.

5. A pesquisa não respondeu à indagação sobre a reação dos pais: se são eles que usam a criança para suas próprias necessidades ou se apenas reagem ao comportamento problemático dos filhos.

A pesquisa da Universidade de Haifa apresenta as mesmas conclusões dos autores: Perera (1986), Colman (1995), Penna e Guidugli (2005), Zweig \& Abrams (1991). Para eles, de modo geral, é difícil que o indivíduo aprenda a suportar seu próprio desconforto e a avaliar a intensidade com um mínimo de objetividade.

Mesmo com a dificuldade em mensurar causa e efeito, os resultados obtidos nesses estudos oferecem informações adicionais que enriquecem o entendimento sobre o fenômeno. Os sintomas nos dizem muito sobre a necessidade de estabelecimento de um diagnóstico diferencial na clínica. São eles: comportamento agressivo, culpa, mecanismos de defesa ativados (cisão, projeção, identificação projetiva), qualidades negativas, hostilidade, depressão, regressão, falta de autoconfiança, retraimento social etc. Algumas constatações que surgiram a partir da pesquisa de Rivka Yahav e Shlomo A Sharlin (2002) clarificam a compreensão sobre o tema. Percebeuse que a criança - scapegoat (expressão inglesa para bode expiatório) - é uma preservadora da unidade familiar e que seus pais têm imensa dificuldade em lidar com os próprios conflitos, o que transforma a criança em receptáculo das crises familiares.

No filme, Conrad é um sobrevivente e sua desconstrução é mostrada em diversas cenas. Após a morte de seu irmão, fica envolto em intensa culpa, por acreditar que poderia ter feito algo que o salvasse do afogamento. Ele é invadido por um sentimento de inadequação acreditando que não agiu de acordo com o que era esperado dele pela sociedade e por sua família. Tomado por essa angústia frente ao impasse do que ele fez e do que ele "deveria ter feito", Conrad exemplifica a condição emocional vivenciada por aquele que é marcado pelo complexo de bode expiatório. Nesses sinais encontra-se uma falha na forma como o indivíduo percebe a experiência.

A rejeição esteve presente na vida de Conrad desde a infância. Em um diálogo com seu pai, este afirma não ter dado atenção necessária ao filho. Conrad sempre percebeu ser preterido em relação ao irmão. Sua mãe, 
excessivamente exigente com ele, também contribuiu para a formação do caráter demasiadamente autoexigente e autocrítico de Conrad.

indivíduo que apresenta o complexo de bode expiatório precisa reprimir suas necessidades, agressivas ou de dependência, quando essas irrompem de forma impulsiva e compulsiva. Elas são vivenciadas com assombro e culpa, quando não são negadas. A tendência da criança/adulto é tentar escapar do lugar de bode expiatório, assumindo um papel de passividade, como o cordeiro sacrificial. A pessoa sente-se como um ser inaceitável diante de si mesmo por não ter sido aceito por seus pais.

Esse indivíduo convive cotidianamente com sentimentos de inadequação diante da vida.

Outro aspecto importante é o desenvolvimento de um ego pessoal imponente, que se sente compromissado a carregar os impulsos não aceitos, vendo-se, dessa forma, como poderoso. Isso proporciona certo sentido de identidade positiva e uma força de enormes proporções, compensando a fragilidade e o masoquismo inerentes ao complexo. Assim, o bode expiatório consegue delinear um papel importante no sistema em que se encontra, fazendo-se elemento necessário, por mais que seja rejeitado.

Conclui-se então que, mesmo que o indivíduo faça a elaboração do seu papel de vítima, e isso é fundamental para seu amadurecimento, ainda assim é muito difícil a saída do círculo vicioso que o envolve nesse fenômeno. A repetição simbólica na representação de papéis é intensa e arraigada. Isso o faz temer se arriscar em novos papéis que poderiam trazer à tona novos sofrimentos e agressões. A manutenção do papel de vítima tem uma função defensiva na dinâmica psíquica e reedita sempre a projeção da responsabilidade no outro, mantendo a culpa pelo seu sofrimento fora de si mesmo.

\section{Considerações finais}

Enumeramos um conjunto de evidências que, ao longo da história, construíram o imaginário em relação à criança na sociedade. $\bigcirc$ sentimento de indiferença em relação à criança se refletiu, durante muitos séculos, justamente na negação de que estas necessitavam de um tratamento diferenciado em função das particularidades da fase infantil. $\bigcirc$ estabelecimento de laços afetivos ficou bastante enfraquecido pelo descaso e insignificância relegados a ela. $\bigcirc$ escalonamento da importância dos filhos dentro do mesmo lar era fato corriqueiro nas famílias do século XIX; além de denotar uma grande dosagem de narcisismo dos pais, à medida que os eleitos eram aqueles que poderiam oferecer algum retorno, evidenciava o caráter discriminatório e excludente que prevalecia naquele meio.

A criança, vista como ente demoníaco, demonstrava a situação de ignorância experimentada pelos homens naquele contexto, onde se 
vivenciava a influência das imagens arquetípicas, desconhecendo-se, contudo que se tratava de produto do inconsciente humano.

A importância dos arquétipos nas relações familiares era ignorada. Desconhecia-se ainda a existência dos pais arquetípicos que fazem parte da psique por meio do inconsciente coletivo, em uma relação de correspondência que permite à criança expressar seu conteúdo interno, em ressonância com o material dos contos de fadas, histórias e mitos. Trata-se de uma necessidade humana a presença das figuras materna e paterna organizando, acolhendo e direcionando o caminho da criança, tanto em seus aspectos psíquicos quanto nos aspectos práticos da vida cotidiana.

Outros arquétipos também estão presentes nas relações familiares, exercendo forte influência na dinâmica estabelecida pelos membros da família. Além do arquétipo paterno existe também o materno, o do velho sábio correspondente ao avô e o da criança. Todos carregando em si um duplo aspecto: negativo e positivo. $O$ arquétipo do irmão traz em si a essência da importância dos relacionamentos sociais e de amizade que são construídos ao longo da vida. $\bigcirc$ sentimento que mantém as relações com a alteridade pauta as relações com o outro ao longo da vida. Dessa forma, percebe-se que cada um deles tem uma importância, acrescentando um norteamento à experiência e à formação da psique infantil.

A manifestação do complexo de bode expiatório também faz pensar sobre a possível relação entre a violência familiar e a constelação deste complexo. $\bigcirc$ estabelecimento de um diálogo surdo, expresso nas atitudes e manifestações daquele, está tomado pelas forças do inconsciente versus um outro, que projeta cegamente os conteúdos inaceitáveis em si, sobremaneira hostil e ultrajante.

Diversos fenômenos podem ser observados dentro da dinâmica familiar. Reações adversas são bastante comuns e frequentes no âmbito doméstico; aceitáveis e toleradas, é claro, a partir de certos limites que preservem a integridade e a dignidade de cada um de seus membros.

As projeções, em seu duplo aspecto, afetam crianças indistintamente por conferirem ao seu alvo atributos aceitáveis ou inaceitáveis da sombra daquele que projeta. Algumas crianças, por não terem sido diferenciadas em seu ambiente familiar, em sua singularidade, são relegadas à função de depositário da sombra dos pais. Partindo desses pressupostos é que se insere a possibilidade da aquisição do complexo de bode expiatório. $\bigcirc$ filme "Gente como a gente" (Schwary, 1980) aponta para essa vertente quando ilustra o tratamento dispensado a Conrad por seus pais.

Um aspecto importante mostrado pelo filme é a interação entre os membros da família. Ela sugere a configuração de uma teia, onde os fios se entrelaçam e, o toque em algum deles, desencadeia, instantaneamente, uma vibração por meio da qual outro fio também recebe o reflexo. As interrelações psíquicas são a pedra de toque da alquimia psíquica humana, onde os psiquismos dos membros de uma família interagem, se misturam e se 
separam, entre outras possibilidades, mas a conclusão desse processo sempre será uma nova substância, uma nova configuração para cada um de seus componentes, a saber: o indivíduo.

\section{Referências}

Alves, J. C. M. (1977). Direito Romano. Rio de Janeiro: Forense.

American Psychiatric Association (APA). (2015). DSM-IV: manual diagnóstico e estatístico de transtornos mentais (5a ed.). Porto Alegre: Artmed.

Ariès P. (2006). História social da criança e da família (2a ed.) Rio de Janeiro: Editora LTC.

Badinter, E. (1985). Um amor conquistado: o mito do amor materno (10a ed.). Rio de Janeiro: Editora Nova Fronteira.

Bartlett, S. (2011). A bíblia da mitologia (1 a ed.). São Paulo: Pensamento.

Brandão, J. S. (2007). Mitologia grega (Vol. III). Petrópolis, RJ: Vozes.

Brasil. (2013). Estatuto da criança e do adolescente (10a ed.). Brasília, DF: Edições Câmara.

Colman, D. A. (1995). Up from scapegoating: Awakening consciousness in groups. Wilmette, Illinois: Chiron Publications.

Descartes, R. (1999). Discurso do método: as paixões da alma. São Paulo: Editora Nova Cultural. (Trabalho original publicado em 1637).

El Hayek, S. (2012). Alcorão Sagrado (15a ed.). São Paulo: Martins Fontes. Jung C. G. (1984). A Dinâmica do Inconsciente. In Obras Completas Nol. VIII). Rio de Janeiro: Editora Vozes. (Trabalho original publicado em 1971).

Neumann, E. (1968). História da origem da consciência. São Paulo: Editora Cultrix.

Neumann, E. (1991). A criança: estrutura dinâmica da personalidade em desenvolvimento desde o início de sua formação. São Paulo: Editora Cultrix.

Perera, S. B. (1986). O complexo de bode expiatório: rumo a uma mitologia da sombra e da culpa. São Paulo: Cultrix.

Pieri, P. F. (Org.). (2002). Dicionário Junguiano. São Paulo: Editora Vozes.

Penna, E. M. D., \& Guidugli, J. M. S. (2015). Complexo de bode expiatório no complexo ego-sombra [on-line]. Psicologia Revista, (20). Recuperado em 10 
março 2016, de http://www.pucclinica/boletim-

clinico/boletim_20/boletim_20_10.htmlsp.br

Yahav, R. \& Sharlin, S. A. (2002). Blame and family conflict: symptomatic children as scapegoats. Child \& Family Social Work, 7(2), 91-98. doi: 10.1046/j.1365-2206.2002.00231.x

Schwary, R. L. (Produtor), \& Redford, R. (Diretor). (1980). Gente como a gente. [DVD]. [s.I.]: Paramount Pictures.

Agostinho [santo]. (2002). Confissões (J. O. Santos, \& A. A. de Pina, trads.). (18a ed.). São Paulo: Editora Nova Cultural. (Trabalho original publicado em 400 d.C.).

Vaithligam, L., \& Sekhar, N. (Orgs.). (2010). Vedas uma introdução à jornada interior (2a ed.). Rio de Janeiro: Fundação Bhagavan Sri Sathya Sai Baba do Brasil.

Zweig, C., \& Abrams, J. (Orgs.). (1991). Ao encontro da sombra: o potencial oculto do lado escuro da natureza humana. São Paulo: Cultrix.

Minicurrículo: Giovana Coutinho - Analista junguiana. Especialista em Temas Filosóficos e Psicologia Médica pela Universidade Federal de Minas Gerais; graduada em Psicologia Clínica pela Universidade Fumec. Especialista em "Dinâmica com Grupos", atualmente se dedica ao atendimento clínico em consultório e a supervisão e produção de material científico na área de psicologia clínica.E-mail: coutinho.giovana@gmail.com 